\title{
Learn Materials: Making an Introductory Online Materials Resource
}

\section{Dr. Soma Chakrabati, Granta Design, Ltd.}

Hannah Melia leads the development of CES EduPack and Granta's Education Hub at Granta Design. She has a degree in Materials Science and Metallurgy and a Post Graduate Certificate in Design, Manufacturing and Management from the University of Cambridge. She has worked in the United States and Germany on medical device design and technology transfer. Over the last 10 years she has interacted with academics that use CES EduPack around the world.

\section{Dr. Kaitlin Tyler, Granta Education Division}

Kaitlin is currently an Education Fellow with the Granta Education Division. She received her PhD at the University of Illinois Urbana Champaign under Professor Paul Braun. Her research was split: focusing on manipulating eutectic material microstructures for optical applications and examining how engineering outreach programs influence participants' self-perceptions of engineering and self-confidence. Her interests lie in materials education and STEM outreach. 


\title{
Learn Materials: Making an introductory, online materials resource (Work in Progress)
}

\begin{abstract}
This year, Granta are hoping to put a very basic database of Materials, Processes and Products online. This database will be open and free and has been designed with two educational purposes in mind. Firstly, as a resource that people can use in outreach activities in the K-12 space, and secondly as a resource that can be used in that first two weeks of an Introduction to Materials course, when students are choosing if Materials is a field that they would like to pursue.

The database would include 20-30 materials, 5-10 of the most important associated properties, and the ability to display the data in a visually engaging manner. It would be interactive and enable students to explore which materials have which properties, in an easily accessible way. It will also contain data for 20 or so Processes and 20 or so Products, so that students can connect Materials knowledge to Products from everyday life and how they are made.

This paper will outline plans, database structures, content and associated resources, and if available by June, a link to a prototype. This is for the purpose of getting feedback from the ASEE Materials community.
\end{abstract}

\section{Introduction}

Materials science and engineering (MSE) is a highly interdisciplinary field, yet still largely unknown in high schools. Thanks to the effort of those doing engineering outreach, this is slowly changing. Outreach serves to increase both awareness and interest for engineering. MSE is often the discipline of choice because of its diverse and tangible nature. For outreach to be successful, it needs to be accessible. Outreach coordinators make it easy to learn about materials with many motivating students by connecting materials to products that are already familiar. By drawing on these previously established links, students can build understanding and see how MSE is related to their own interests. Supporting educational software is now wide-spread in schools.

Granta Design strives to support materials education and currently does so in a variety of ways. The main form of support is through the CES EduPack software, which supports materials and manufacturing processing related courses at the collegiate level. Alongside the software is our Education Hub. Here, over 350 resources that support engineering teaching for a variety of disciplines and levels can be found. But Granta does more than provide tools for the classroom. They also help host materials education symposia, bringing together educators from around the world to discuss best practices and learn from one another. These support avenues are largely focused at higher education, so there is a need to simplify and improve access to content to support outreach.

To address this, Learn Materials is being created. This is a summary of our work towards developing support for educators carrying out STEM outreach to High Schools. Learn Materials will be a web-based database that is free, no password needed. This highly interactive format 
runs on a web browser, making it accessible to those in K-12 schools and other outreach venues. In this paper, a general overview of how Learn Materials works and suggestions of where it can be used will be discussed. We also put out a call to the materials education community for feedback in specific areas to ensure Learn will be useful to those who want to use it.

\section{Learn Materials: An Overview}

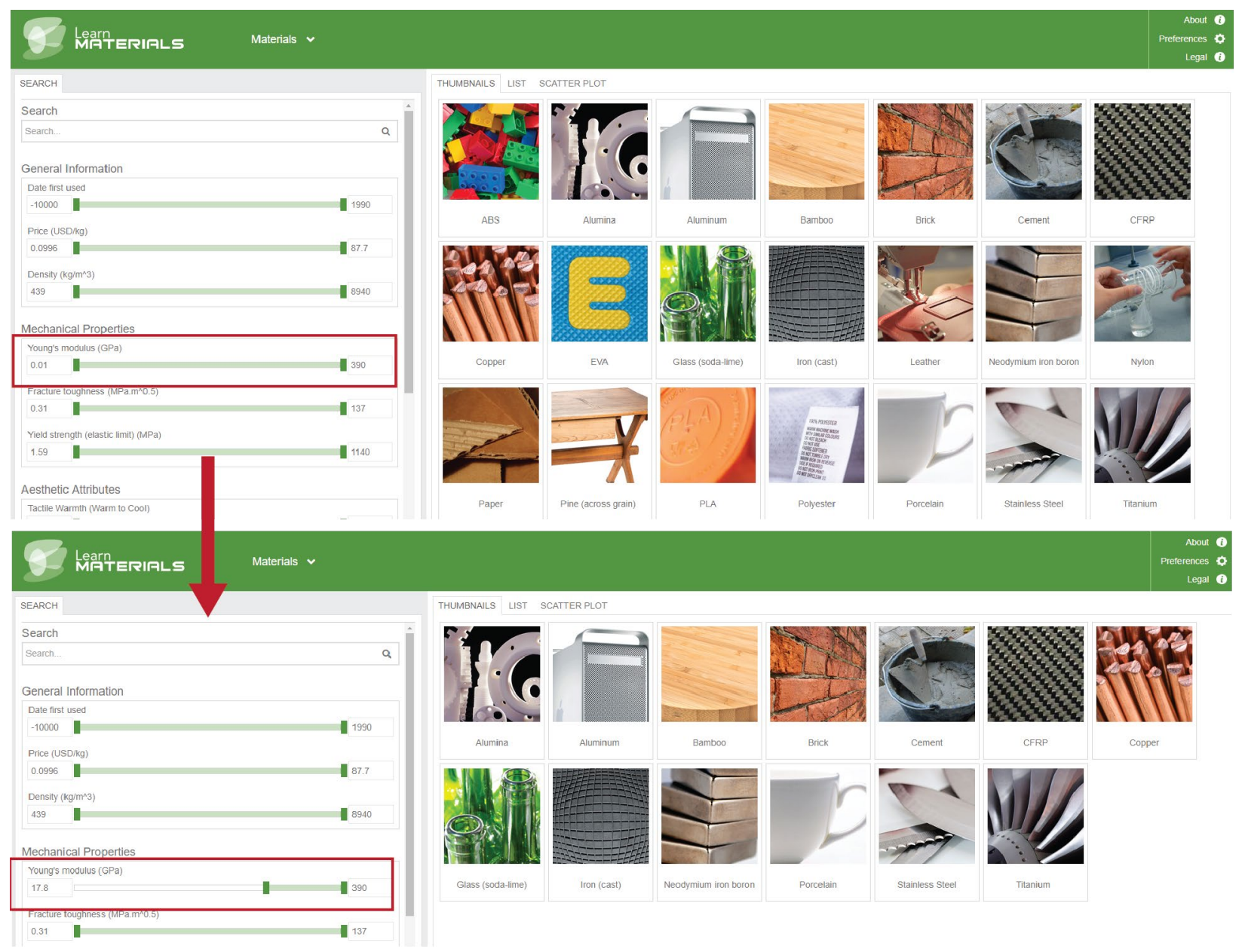

Figure 1: A Mock Up of the Learn Materials Main Interface

Records are shown pictorially, and properties are adjustable with sliders where appropriate to increase engagement. The change between the top and the bottom image shows how, as the slider moves, materials disappear from the available list.

As stated, Learn Materials will exist as a web browser database. A mockup of the main interface and how it can be used to dynamically show changes in materials/properties/products based on different properties is shown in Figure 1. Notice the pictures; the goal of this database is to be as engaging as possible for use in outreach and other K-12 ventures. By including pictures when possible, students can more easily connect with topics familiar to them. The design with large photos and sliders to allow for adjusting values of properties should be intuitive to students, making it faster to use and therefore build knowledge. Three main databases, shown in Figure 2, will be used. 


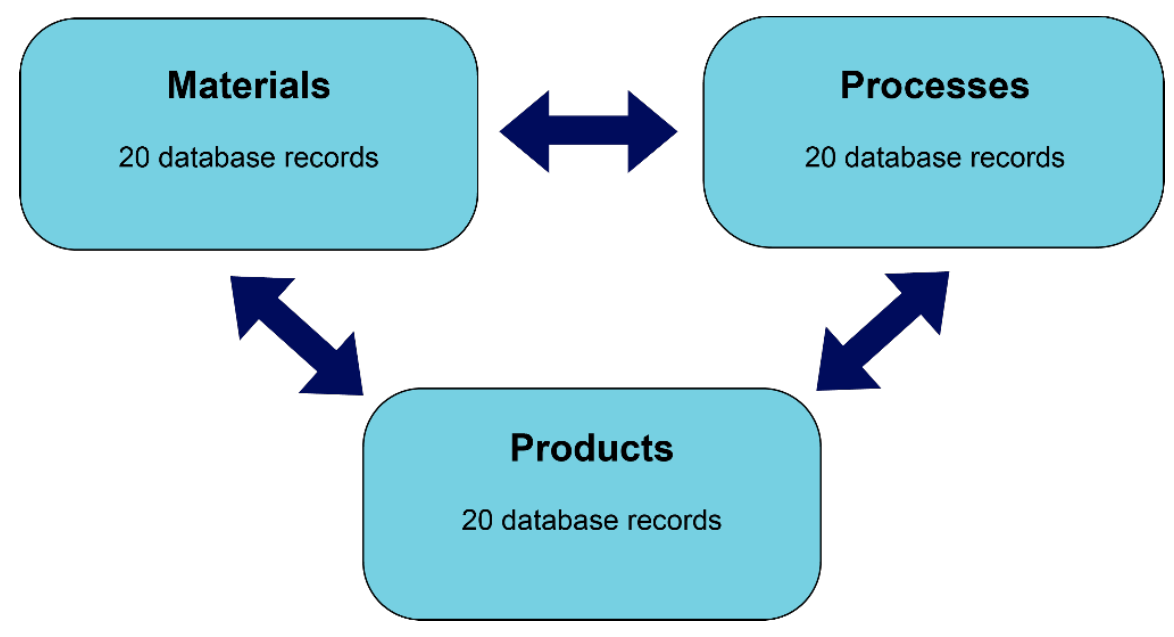

Figure 2: Schematic showing the databases and their connections for Learn Materials. Number of records is approximate

Each record in a database will be linked to a minimum of two records in the other databases, showing the high degree of connectivity between materials and the processes that create and shape them into the products we used in every-day life. This grounding in real world applications can be used to show the value of materials science to those experiencing it for the first time, assisting educators in increasing the field's interest. The records and associated properties were chosen with a high school audience in mind; all are common in everyday life so personal connections can be readily made. This commonality could make this tool useful for a basic introductory engineering course as well, particularly a broad discipline overview or freshman cornerstone course. Figures 3 and 4 showcase mockup material and product database images, while Table 1 provides a working list of the three database records. Names have been simplified to make them as easily understood as possible.

Table 1: Working Learn Materials Database Records

\begin{tabular}{|l|l|l|l|}
\hline Database & Materials & Processes & Products \\
\hline \multirow{5}{*}{ Records } & Glass & $\begin{array}{l}\text { Grinding and } \\
\text { polishing }\end{array}$ & Camera \\
\cline { 2 - 4 } & Alumina & Sand casting & Casserole Dish \\
\cline { 2 - 4 } & Porcelain & Vitreous enameling & $\begin{array}{l}\text { Armand desaegher } \\
\text { and octave aubecq }\end{array}$ \\
\cline { 2 - 4 } & Brick & Extrusion & Cheese grater \\
\cline { 2 - 4 } & Cement & Layup Methods & Arforio for Alessi \\
\cline { 2 - 4 } & Iron & Screen printing & Converse \\
\cline { 2 - 4 } & Stainless Steel & Injection molding & Blue headphones \\
\cline { 2 - 4 } & Aluminum & Stamping & iPhone \\
\cline { 2 - 4 } & Titanium & $\begin{array}{l}\text { Compression } \\
\text { molding }\end{array}$ & Humpty dumpty chair \\
\cline { 2 - 4 } & Copper & Threaded fasteners & Bicycle \\
\cline { 2 - 4 } & EVA & Wire drawing & Longboard \\
\cline { 2 - 4 } & ABS & TIG welding & Legos \\
\hline
\end{tabular}




\begin{tabular}{|l|l|l|l|}
\hline & Nylon & Laser cutting & Dyson \\
\cline { 2 - 4 } & Polyester & Milling & Radiant light film \\
\cline { 2 - 4 } & PLA & 3D printing & Zhi shelves \\
\cline { 2 - 4 } & Paper & Rigid adhesives & Electrical wire \\
\hline & Pine & Drilling & Bike \\
\cline { 2 - 4 } & Bamboo & & Titanium camera \\
\hline & Leather & & Shelving system \\
\hline & CFRP & Wave \\
\cline { 2 - 4 } $\begin{array}{l}\text { Neodymium iron } \\
\text { boron }\end{array}$ & & Cardboard Chair \\
\hline & & Ceramic Speaker \\
\hline
\end{tabular}

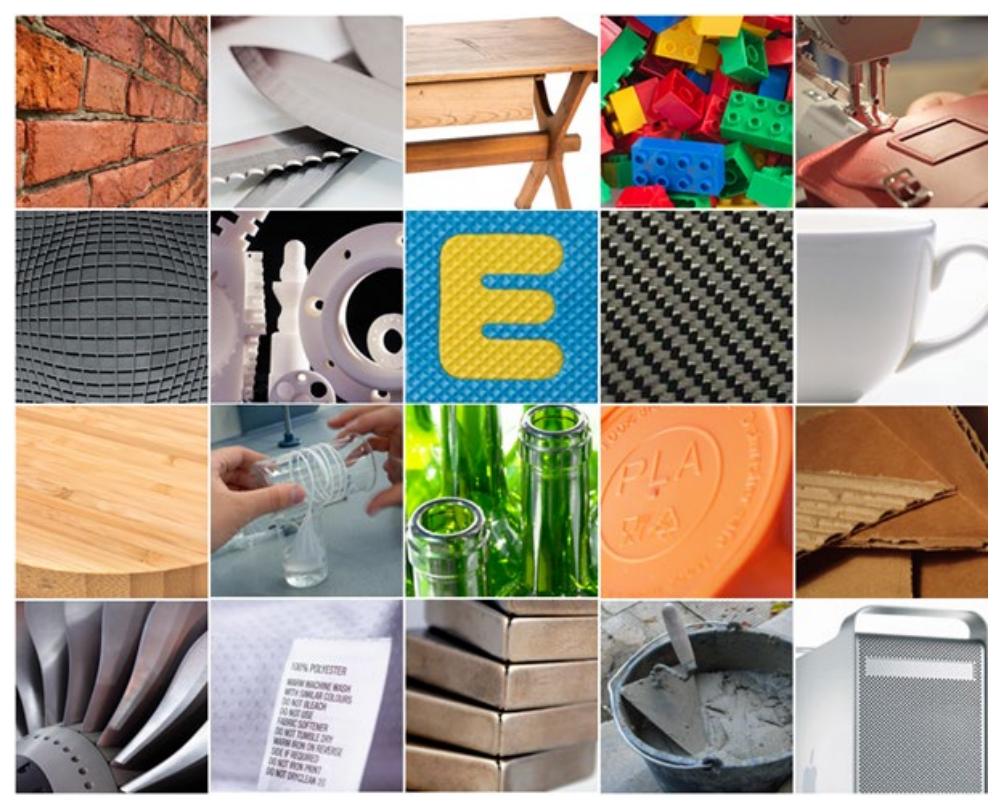

Figure 3: Working Materials Photos to go with materials list from Table 1 


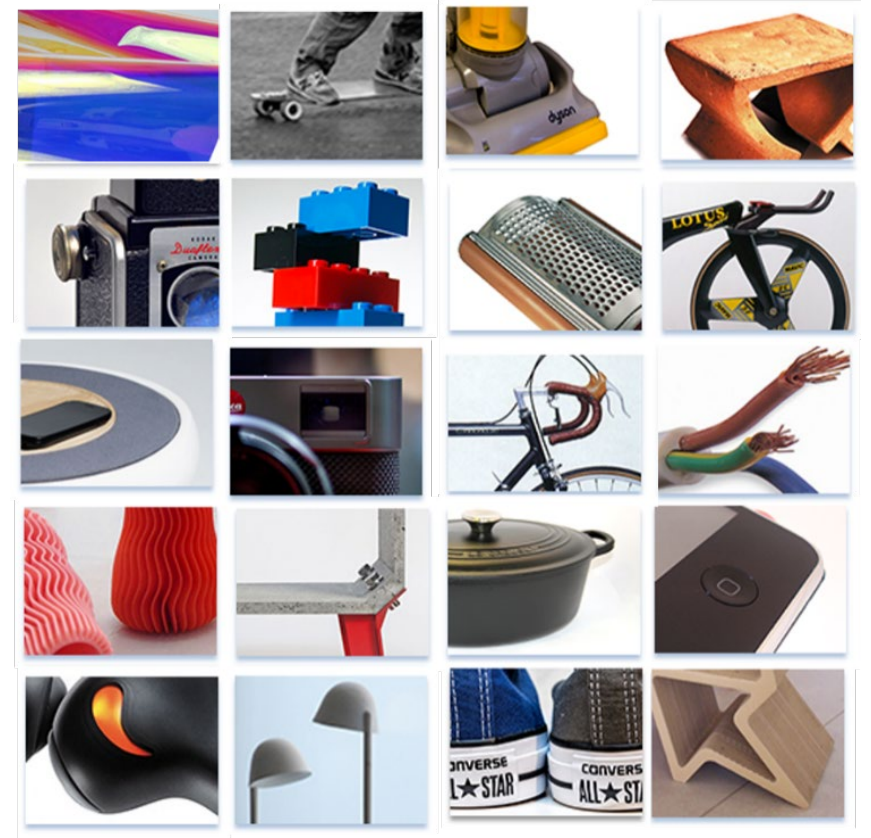

Figure 4: Working Products Photos to go with products list from Table 1

Materials science is more than just the materials and the processes that make them into products. Properties are a key area that will also be included. Each database will have different properties associated with each record (see Table 2). These were chosen for their importance and relevance to a broad range of disciplines so that the value of understanding them can be highlighted to students interested in Mechanical Engineering, Industrial Design, and the environment. As was highlighted before, Figure 1 shows sliders for properties where appropriate. That way, students can quickly see which materials, processes, and products have which properties and get a "feel" for how these vary for different material classes. Properties can also be plotted, similarly to in CES EduPack, to compare differences in records (see Figure 5). Figure 6 shows an example of these records for both materials and processes.

Table 2: Working List of Properties for Learn Materials Databases

\begin{tabular}{|l|l|l|l|}
\hline Database & Materials & Processes & Products \\
\hline \multirow{5}{*}{ Properties } & Date first used & $\begin{array}{l}\text { Material } \\
\text { compatibility }\end{array}$ & Category \\
\cline { 2 - 4 } & Price & Shape & $\begin{array}{l}\text { Year of first } \\
\text { production }\end{array}$ \\
\cline { 2 - 4 } & Density & Economic batch size & Style influence \\
\cline { 2 - 4 } & Young's Modulus & Relative cost index & Material types \\
\cline { 2 - 4 } & Yield Strength & & Production Scale \\
\cline { 2 - 4 } & Tactile Warmth & & \\
\cline { 2 - 4 } & Pitch & & \\
\cline { 2 - 4 } & Melting Point & & \\
\cline { 2 - 4 } & $\begin{array}{l}\text { Thermal } \\
\text { Conductivity }\end{array}$ & & \\
\hline
\end{tabular}




\begin{tabular}{|l|l|l|l|}
\hline & Electrical Resistivity & & \\
\cline { 2 - 4 } & Carbon Footprint & & \\
\cline { 2 - 4 } & Can it be recycled? & & \\
\hline
\end{tabular}

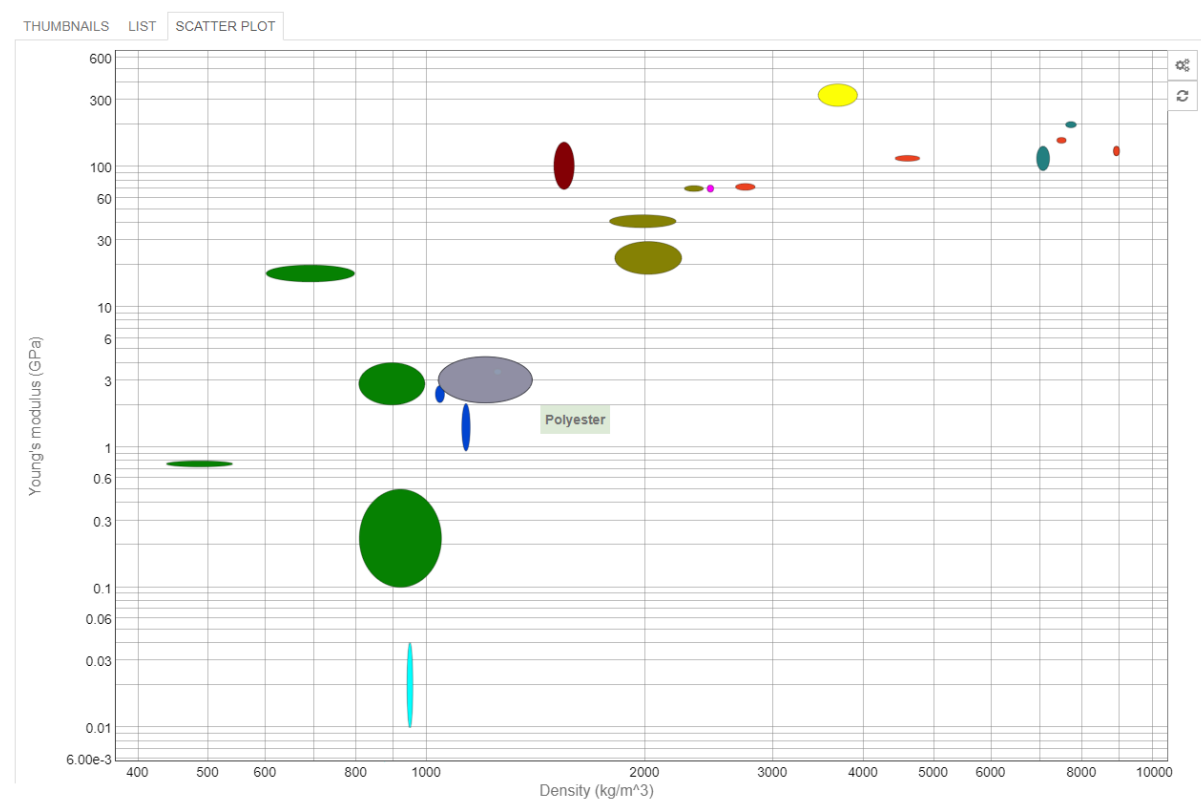

Figure 5: Example Property Comparison Plot
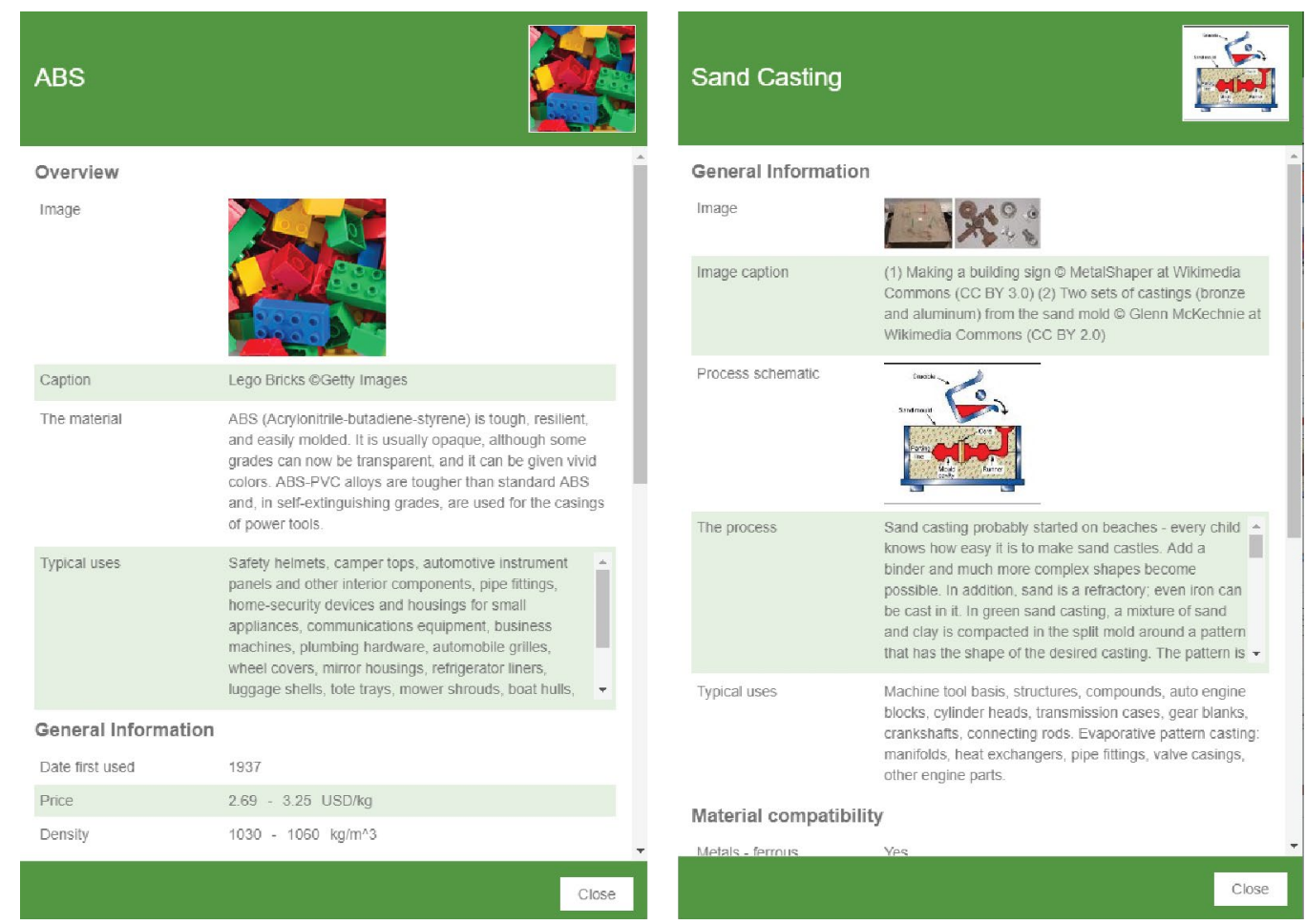

General Information

Image

Image caption (1) Making a building sign @ Metalshaper at Wikimedia Commons (CC BY 3.0) (2) Two sets of castings (bronze and aluminum) from the sand mold $\Theta$ Gienn Mckechnie at Whimedia Commons (CC EY 2.0)
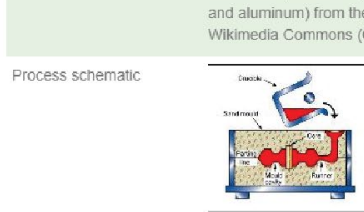
The process $\quad$ Sand casting probably started on beaches - every child knows how easy it is to make sand castles. Add a binder and much more complex shapes become possible. In addition, sand is a refractory, even iron can be cast in it. In green sand casting, a mxture of sand and clay is compacted in the split mold around a pattern that has the shape of the desired casting. The pattem is -
Machine tool basis, structures, compounds, auta engine Dlocks, cylinder heads, transmission cases, gear blanks. crankshăts, connecting rods. Evaporative pattem casting: manifolds, heat exchangers, pipe fittings, value casings,

Material compatibility

Figure 6: Example Records for Materials and Processes Records 
Our hope is the combination of these properties, with the different material, processes, and products records, can help students explore real world materials problems in a fun and engaging way.

\section{Help from the Community}

It would be helpful at this stage to get feedback from educators that deliver STEM outreach programs, to make sure that Learn Materials is as good as it could be. Once a prototype of Learn Materials is available, we want to know what you think. Particularly, we are interested in your feedback in the following areas:

1. Do you feel the set of materials is appropriate?

2. Do you feel the processes are simple enough for students to understand quickly?

3. Do you feel the products are well known and easy for students to recognize?

4. Do you feel the set of properties for each database is appropriate?

5. With what you have seen, is this tool targeted at the right audience? We are hoping to target high school aged students

\section{Classroom Incorporation}

The main purpose of this paper is to introduce a new materials teaching tool and to get feedback from the community. We did, however, want to introduce a few ideas of how to use this in a classroom. These include:

- Play a guessing game — what is the lightest material? The most bendy?

- Guess what the principle materials are in a product

- Find out which materials work with which processes and why

- Pick the best material for a product given a simple set of criteria

In the future, resources such as microprojects will be created to support K-12 teachers who want to introduce engineering into their classes. We would also be looking to collaborate on resources to ensure that the appropriate education level is met for various grades, classes, etc.

\section{Conclusion}

MSE is a common topic in outreach, but its diverse nature can make it difficult for software to support these endeavors. With Learn Materials, we at Granta hope to assist educators in their outreach efforts by providing a highly interactive, free to use, web-based tool. By highlighting materials and products students will already be familiar with and connecting those to common processes and properties, real world examples can be used to build authentic materials knowledge at an early age and highlight the value in studying materials. Granta has always supported the materials education community at the collegiate level and we hope to expand our support to K-12 with this resource. 